\title{
CIRURGIA DE RECONSTRUÇÃO DE ORELHA MÉDIA
}

\author{
MIDDLE EAR RECONSTRUCTION
}

Eduardo T. Massuda

Médico Assistente. Divisão de Otorrinolaringologia. Hospital das Clínicas da Faculdade de Medicina de Ribeirão Preto-USP. Correspondência: Departamento de Oftalmologia, Otorrinolaringologia e Cirurgia de Cabeça e Pescoço. Divisão de Otorrinolaringologia. Hospital das Clínicas da Faculdade de Medicina de Ribeirão Preto-USP.

Avenida Bandeirantes, 3.900 - Campus Universitário da USP. 14.048-900 Ribeirão Preto - SP.

Fone (16) 3602-2863 - Fax (16) 3602-2860 - Email: edutmassuda@ig.com.br

Massuda ET. Cirurgia de reconstrução de orelha média. Medicina (Ribeirão Preto) 2005; 38 (3/4): 253-256.

RESUMO: A orelha média funciona como um amplificador sonoro. Utiliza para isso três mecanismos: o hidráulico, a alavanca dos ossículos e o jogo das janelas, sendo o mais importante o fato da energia mecânica captada pela membrana timpânica ser concentrada na área da janela oval, que é muitas vezes menor (mecanismo hidráulico).

Podemos dividir o não funcionamento da cadeia ossicular em duas categorias: com diminuição da vibração da cadeia e com interrupção da cadeia. Neste artigo, o autor discorre sobre os problemas da cirurgia de reconstrução.

Descritores: Ossículos da Orelha. Orelha Média. Reconstrução. Cirurgia.

\section{1- INTRODUÇÃO}

A orelha média desenvolveu-se graças a mutações subsequientes na escala filogenética. A saída do meio aquático, durante o desenvolvimento das espécies, fez com que houvesse a necessidade da formação de um sistema em que não ocorresse dissipação de energia sonora na interface entre meio aéreo (orelha externa) e líquido (orelha interna). Assim, a membrana timpânica e os ossículos, se formaram para a otimização desta transmissão.

Existem três mecanismos na anatomofisiologia da orelha média, que são fundamentais para que não haja dissipação da energia sonora:

a- Hidráulico: a membrana timpânica tem uma área 20 vezes maior do que a janela oval. Desta forma, ocorre uma grande concentração da energia sonora captada pela área total da membrana timpânica, quando transmitida por uma área muito menor.

b- Alavanca ossicular: o martelo articula-se com a bigorna. O cabo do martelo fica mais anteriorizado e mais inferior (aproximadamente 1,4mm) do que a apófise longa da bigorna, produzindo assim um mecanismo de alavanca que amplifica a energia transmitida.

c- Jogo de janelas: quando a platina da janela oval empurra a perilinfa da orelha interna, devido à vibração em pistão do estribo, a janela redonda faz o trajeto oposto, liberando sua energia em direção à orelha média.

O mais importante destes três mecanismos é o mecanismo hidráulico, o qual produz um ganho de 27 a $30 \mathrm{~dB}$ (decibéls). Assim, a integridade dos ossículos é de fundamental importância para que não haja perda da capacidade auditiva. 


\section{2- PATOGÊNESE DA DISFUNÇÃO DA CADEIA OSSICULAR}

Podemos dividir o mau funcionamento dos ossículos em duas categorias: a primeira com diminuição da vibração da cadeia ossicular, como ocorre na timpanoesclerose e na otospongiose, e a segunda com interrupção da cadeia ossicular, como nos casos de desarticulação. Neste último caso, a principal causa é a otite crônica, seja ela colesteatomatosa ou não, sendo outra causa muito frequiente os traumatismos de osso temporal.

A otospongiose, ou otosclerose fenetral, é uma doença genética onde ocorre um foco otosclerótico que invade o ligamento anular na ante-fenestra da janela oval causando assim a diminuição de sua vibração e conseqüentemente dos líquidos no interior da cóclea. Assim, temos a transmissão óssea da audição normal e a transmissão área diminuída, caracterizando uma surdez de condução. Se o gap aéreo-ósseo for maior ou igual a $30 \mathrm{~dB}$ a correção pode ser feita cirurgicamente, através de um procedimento denominado estapedotomia, o qual costuma ter ótimos resultados auditivos.

\section{3- TIPOS DE RECONSTRUÇÃO OSSICULAR}

A estapedomia corresponde à retirada do estribo e colocação de uma prótese em seu lugar, através de uma pequena perfuração na janela oval, a prótese colocada fica, assim, em contato com a perilinfa da orelha interna (Figura 1).

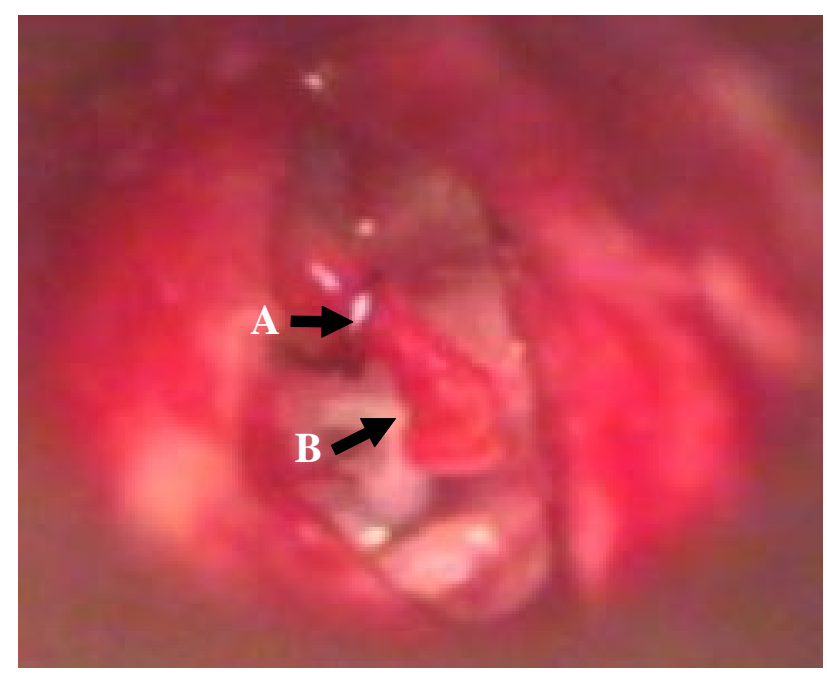

Figura 1: Prótese de estapedotomia posicionada. A) Nota-se o anel metálico envolvendo o ramo longo da bigorna. B) Porção de teflon da prótese de estapedotomia.
A timpanosclerose corresponde a hialinização da mucosa da orelha média, ou mesmo da membrana timpânica, devido a alterações crônicas, seja por otorréia crônica, por otites médias de repetição, ou por alteração imunológica da mucosa da orelha média. Esta hialinização, por sua vez, evolui para uma calcificação, o que leva a uma diminuição da capacidade vibratil da cadeia ossicular (Figura 2).

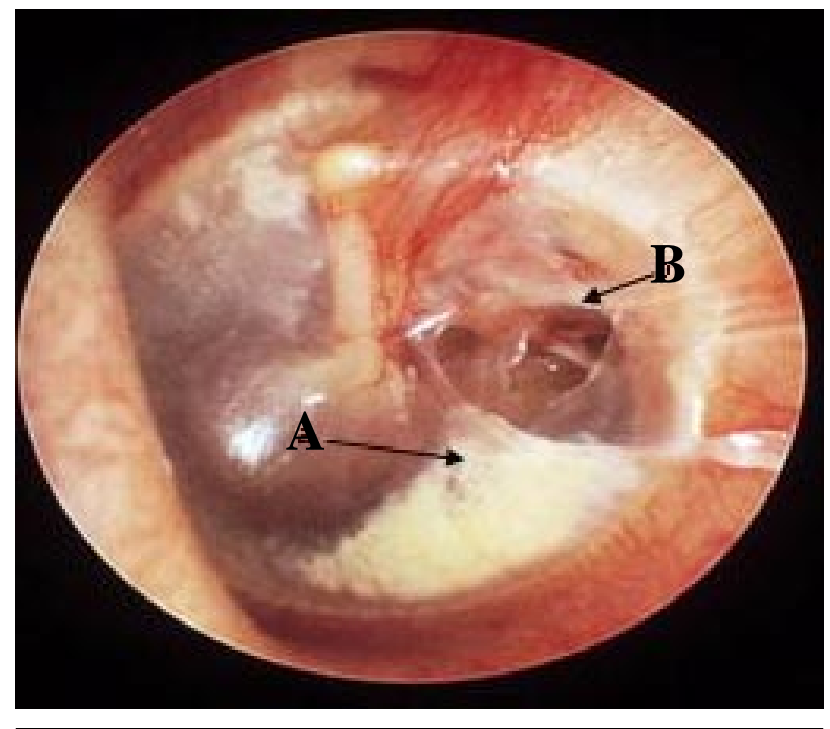

Figura 2: Coloração esbranquiçada característica da timpanosclerose. A) Miringosclerose, B) Timpanosclerose envolvendo a bigorna.

As desarticulações da cadeia ossicular causam perda auditiva condutiva superior a $40 \mathrm{~dB}$, normalmente. possíveis:

Existem várias combinações de desarticulações

- martelo e estribo presentes, ausência de bigorna ou corrosão do ramo longo da bigorna, o que corresponde a $40 \%$ dos casos;

- martelo presente, estribo e bigorna ausentes, platina do estribo móvel, correspondendo a $20 \%$ dos casos;

- martelo e bigorna ausente e estribo presente, platina móvel, correspondendo a $30 \%$ dos casos;

- martelo, bigorna e estribo ausentes, platina móvel, em 8 a $2 \%$ dos casos;

- martelo e estribo ausentes e bigorna presente, menos de $1 \%$ dos casos;

- martelo, bigorna e estribo ausente e com platina fixa correspondem a $1 \%$ dos casos. 
Na prática o que devemos observar, do ponto de vista da correção cirúrgica, é se há estribo e se sua mobilidade está preservada. Quando temos a supraestrutura do estribo intacta, as reconstruções têm melhores chances de bom funcionamento. Os melhores resultados estão nos casos com martelo e estribo presentes e os piores são aqueles onde temos platina fixada por timpanoesclerose e sem cadeia ossicular. Neste último caso, é necessário sempre realizar ossiculoplastia em 2 tempos cirúrgicos, se houver membrana timpânica perfurada. No primeiro tempo, fechase a membrana e, no segundo tempo, faz-se uma estapedotomia na área de timpanosclerose que está bloqueando a platina.

As reconstruções podem ser realizadas com enxertos autólogos ou com próteses bioativas e biocompatíveis. Elas são denominadas TORP - Total Ossicular Reconstruction Prosthesis (Figura 3) se fizerem efeito columelar total, ou seja, da platina até membrana timpânica ou PORP - Partial Ossicular Reconstruction Prosthesis (Figura 4) se for parcial como nos casos onde ainda temos o estribo intacto.

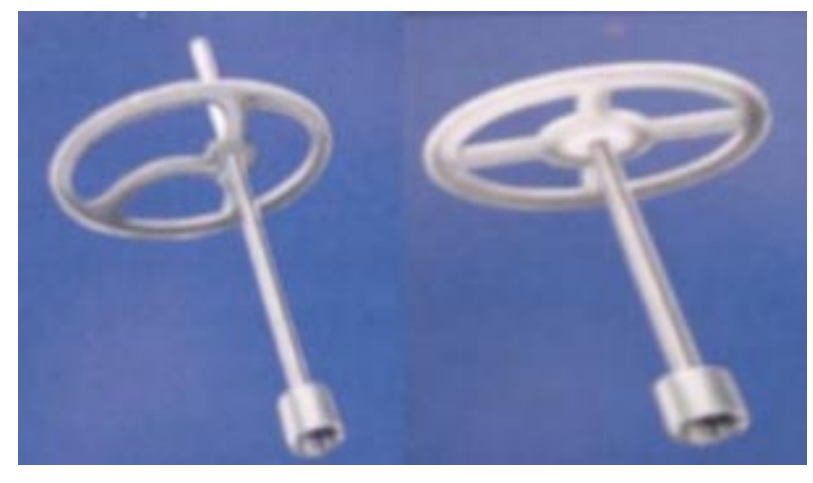

Figura 3: Prótese tipo TORP.

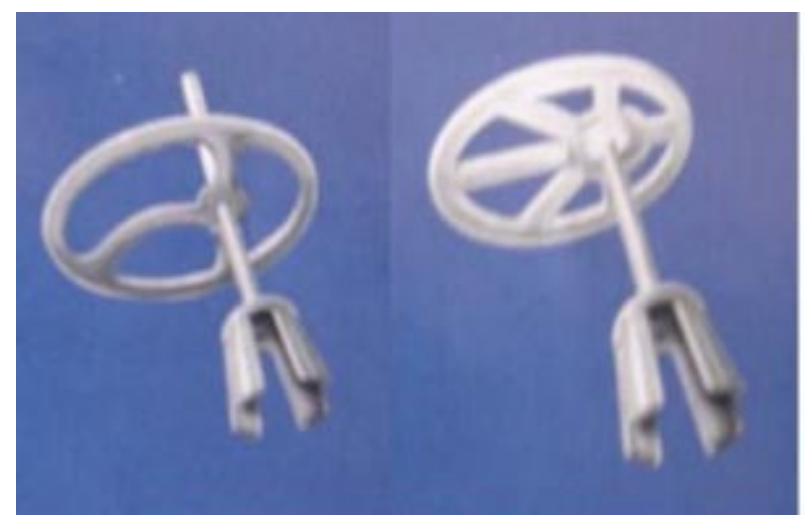

Figura 4: Prótese tipo PORP.
Vários materiais são utilizados como enxerto: cerâmica (bioglass), plastipore, proplast, titânio, cartilagem (Figura 5), a própria bigorna do paciente remodelada (Figura 6) ou córtex da mastóide remodelada. No nosso serviço o que mais utilizamos é a cartilagem e a bigorna ou córtex da mastóide remodelada. Na literatura, muitos trabalhos demonstram que pode haver extrusão do material enxertado; mesmo a bigorna remodelada pode ser extruída. Assim, recomendamos a colocação de um pequeno fragmento de cartilagem quando colocamos o enxerto diretamente sob a membrana timpânica, para impedir o contato entre os dois e a expulsão do material.

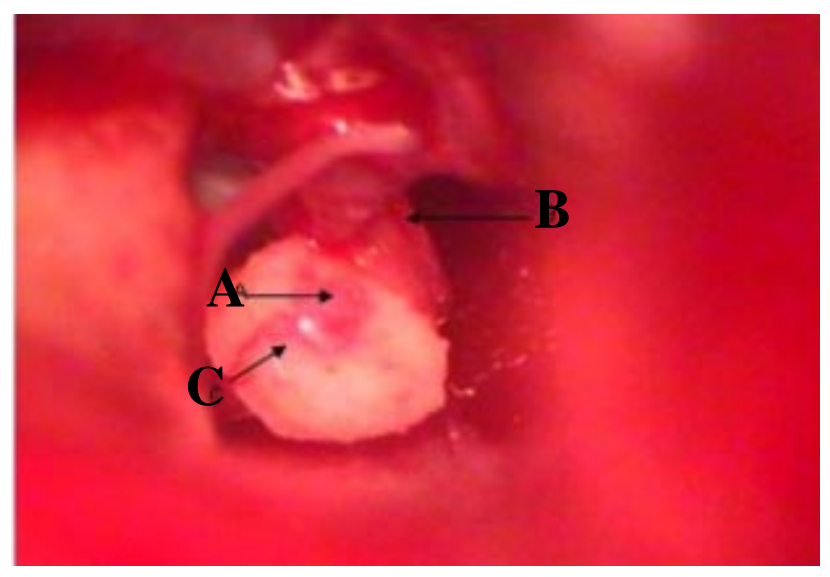

Figura 5: Enxerto de cartilagem posicionado. A) Vascularização do B) Enxerto de cartilagem, C) Membrana timpânica remanescente.

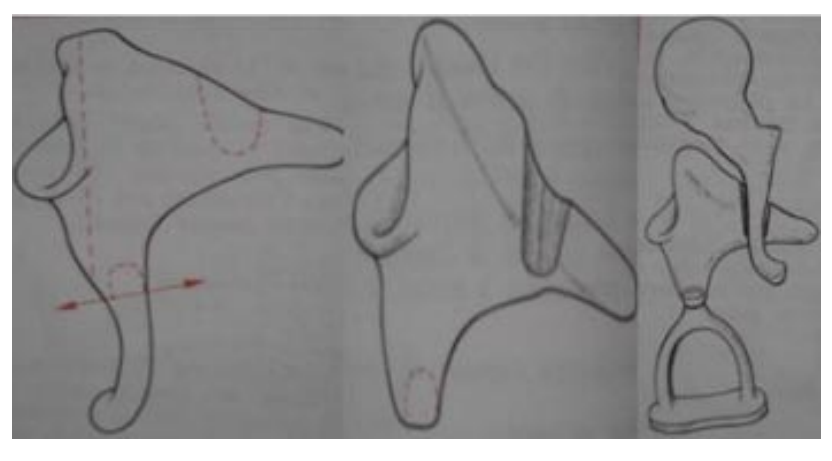

Figura 6: Esquema de remodelação da bigorna para posicionamento entre martelo e estribo.

Quando o martelo está presente, deve-se tentar posicionar o enxerto fixando-se a ele, quanto mais pontos de fixação forem produzidos na ossiculoplastia, melhor o resultado, porém se o martelo estiver posicionado de forma muito anteriorizada, deverá ser realizada a liberação do tendão do músculo tensor timpanal, para melhor mobilização deste ossículo. 


\section{4- RESULTADOS DAS OSSICULOPLASTIAS}

O fechamento do gap aéreo-ósseo constitui o melhor indicador do êxito da reconstrução ossicular. $\mathrm{Na}$ estapedotomia, este fechamento é provável em cerca de $90 \%$ dos nossos casos, pois a técnica cirúrgica é realizada em orelha média normal, apenas com calcificação na platina do estribo; em $1 \%$ os casos ocorre morte coclear com perda total da audição da orelha operada. Em ossiculoplastias o fechamento total do gap só é possível em 10 a $20 \%$ dos casos. A maioria (60\% dos casos, em média) ficará com gap de $25 \mathrm{~dB}$.

Como se pode perceber, a cronicidade da doença é o maior fator de insucesso das ossiculoplastias. Assim, em otites médias crônicas com colesteatoma, as ossiculoplastia devem ser realizadas em segundo tempo, geralmente após 12 meses da primeira cirurgia, ou seja, após remoção com sucesso da patologia de base, nos casos de cirurgia com técnica fechada. $\mathrm{Na}$ técnica aberta, tenta-se realizar em um só tempo cirúrgico.

Os melhores resultados de reconstrução da cadeia ossicular são encontrados nos casos de trauma de osso temporal com desarticulação de cadeia, pois a orelha média não apresenta doença crônica.

Em casos onde a mucosa da orelha média en- contra-se muito espessada, em virtude da inflamação crônica, pode-se optar pela colocação de um fragmento de silastic na orelha média, fundamental para melhor controle da infecção.

Devem-se observar sempre as condições da ventilação atical (área da membrana de Schrapnell); muitas vezes faz-se necessária a secção do tendão do tensor timpânico, porém este procedimento causará menor estabilidade da ossiculoplastia. Este procedimento será necessário também em casos de martelo muito anteriorizado e medializado.

Outra causa de falha no resultado cirúrgico é a manutenção da tuba auditiva impermeável, o que leva as retrações timpanais após alguns anos de cirurgia. Temos por conduta utilizar enxerto duplo nestes casos, utilizando fáscia do músculo temporal e cartilagem do tragus para refazer a membrana timpânica.

\section{5- CONCLUSÕES}

A estapedotomia apresenta ótimos resultados quando comparada a ossiculoplastia, pois não existe doença crônica na orelha média, o tímpano está intacto, a mucosa é normal e sua tuba auditiva funciona bem. A cronicidade da doença da orelha média é o principal fator de falha na ossiculoplastia.

Massuda ET. Middle ear reconstruction. Medicina (Ribeirão Preto) 2005; 38 (3/4): 253-256

ABSTRACT: Middle ear works as a sound amplifier. Three kinds of mechanism are used for this purpose: the hydraulic, the ossicular lever and the windows set. The most important of them is concentration of vibratory energy in the oval windows. (hydraulic mechanism).

We can divide the disfunctions of the ossicular chain in two categories: with reduction of the chain vibration and with interruption of the ossicular chain. In this article we will report the problems that may occur in the surgery of the reconstruction of the ossicular chain.

Keywords: Ear Ossicles. Ear, Middle. Reconstruction. Surgery

\section{BIBLIOGRAFIA RECOMENDADA}

Charachon R. La tympanosclérose. In: Magnan J, ed. L'otite chronique. $1^{\circ} \mathrm{ed}$. Marseille: Arnette Blackwell; 1994. p. 101-3.

Desaulty A, Shahsavari S, Pasquesoone X. La reparation ossiculaire par autogreffe en type III. Rev Laryngol Otol Rhinol 2005; 126: 19-23.

Fisch U. Ossiculoplasty. In: Fisch U, ed. Tympanoplasty, mastoidectomy, and stapes surgery.Stuttgart: Thieme Medical Publishers; 1994; p. 44-118.
Gersdoff M, Maisin JP, Munting E. Comparative study of the clinical results obtained by means of plastipore and ceramic ossicular prosthesis and bone allografts. Am J Otol 1986; 7: 294-7.

Grote JJ. Reconstruction of the ossicular chain with hydroxyapatitre implants. Ann Otol Rhinol Laryngol 1986, (Suppl 123): 10-2.

Lacher G. Les homogreffes tympano-ossiculaires. Rev Laryngol Otol Rhinol 1986; 107: 193-7.

Portmann M. Audition et communication. Conference d'Eméritat. Rev Laryngol Otol Rhinol 1993; 114: 77-82. 